\title{
COMUNICAR-SE COM O PACIENTE SEDADO: VIVÊNCIA DE QUEM CUIDA ${ }^{1}$
}

\author{
Gabriela Rodrigues Zinn ${ }^{2}$ \\ Maria Júlia Paes da Silva ${ }^{3}$ \\ Sandra Cristina Ribeiro Telles ${ }^{4}$
}

Zinn GR, Silva MJP, Telles SCR. Comunicar-se com o paciente sedado: vivência de quem cuida. Rev Latino-am Enfermagem 2003 maio-junho; 11(3):326-32.

Como interagir com pacientes sedados aparentemente incapazes de se expressar? A partir desse questionamento decidimos pela realização de estudo qualitativo, norteado pela vertente da fenomenologia, com o objetivo de compreender o comunicar-se com o paciente sedado, a partir da perspectiva das enfermeiras que cuidam desses pacientes. Foram realizadas 10 entrevistas individuais com enfermeiras intensivistas de um Hospital Escola de São Paulo e, após a análise dos dados, desvelou-se quatro categorias temáticas: comunicação com o paciente sedado x grau de sedação; comunicação com o paciente sedado x capacidade de percepção atribuída; valorização da comunicação com o paciente sedado; formas de comunicação com o paciente sedado. Concluiu-se, então, que a comunicação com o paciente sedado existe e que ocorre em diferentes momentos e de formas distintas, através do verbal e do não-verbal.

DESCRITORES: comunicação, inconsciência, unidades de terapia intensiva

\section{COMMUNICATING WITH THE SEDATED PATIENT: EXPERIENCE OF THE CARETAKERS}

How can we interact with sedated patients who are seemingly unable to express themselves? On the basis of these questions, we chose to realize a qualitative phenomenological study aimed at comprehending communication with the sedated patient from the perspective of the nurses who take care of those patients. Ten individual interviews were realized with intensive nurses from a Hospital School in São Paulo. After data analysis, four general thematic categories were revealed: communication with sedated patient $x$ sedation degree; communication with sedated patient $x$ attributed perception capacity; valuation of communication with sedated patient; forms of communication with the sedated patient. This research concluded that the communication with the sedated patient exists and occurs at different moments and in different ways through verbal and nonverbal communication.

DESCRIPTORS: communication, unconsciousness, intensive care units

\section{COMUNICARSE CON EL PACIENTE SEDADO: VIVENCIA DE QUIEN CUIDA}

Cómo interactuar con pacientes sedados e aparentemente incapaces de expresarse? A partir de esta interrogante, decidimos realizar un estudio cualitativo, orientado por la vertiente de la fenomenología, con el objetivo de comprender "el comunicarse con el paciente sedado", a partir de la perspectiva de enfermeras que cuidan de estos pacientes. Se realizaron 10 entrevistas individuales con enfermeras intensivistas de un hospital docente de São Paulo y después del análisis de los datos, se descubrieron cuatro temas generales: comunicación con el paciente sedado x grado de la sedación; comunicación con el paciente sedado x capacidad de la opinión atribuida; valorización del comunicarse con el paciente sedado; formas de comunicación con el paciente sedado. Se concluye entonces que la comunicación con el paciente sedado existe y que esta ocurre en diferentes momentos y de diversas formas, a través de lo verbal y no verbal.

DESCRIPTORES: comunicación, inconsciencia, unidades de terapia intensiva

\footnotetext{
${ }^{1}$ Trabalho atribuído ao Departamento de Enfermagem Médico-Cirúrgica da Escola de Enfermagem da Universidade de São Paulo e ao Departamento de Enfermagem do Hospital Universitário de São Paulo; ${ }^{2}$ Enfermeira Assistencial da Unidade de Terapia Intensiva do Hospital Universitário de São Paulo, e-mail: gabizinn@yahoo.com.br; ${ }^{3}$ Professor Livre Docente da Escola de Enfermagem da Universidade de São Paulo, e-mail: juliaps@usp.br; ${ }^{4}$ Enfermeira Chefe da Unidade de Terapia Intensiva do Hospital Universitário de São Paulo, e-mail: sa.telles@zipmail.com.br
} 
INTRODUÇÃO

A Enfermagem é a arte e a ciência do cuidar, cuidar de pessoas! E para que isso seja viável é necessário um processo de interação entre quem cuida e quem é cuidado, é necessária troca de informações e de sentimentos entre essas pessoas.

Refletindo sobre essa afirmação e transpondo-a para a realidade de uma unidade de terapia intensiva (UTI), onde encontramos muitos pacientes com alteração em seu nível de consciência, chegamos ao seguinte questionamento: "Como interagir com pacientes sedados, aparentemente incapazes de se expressar?"

Sabemos que a comunicação destaca-se como o principal instrumento para que a interação e a troca aconteçam e, conseqüentemente, o processo de cuidar, no seu sentido mais amplo, tenha espaço para acontecer; afinal, "os componentes da comunicação formam o clima e a nutrição para a compreensão"(1).

Mas o que é comunicação? Etimologicamente, a palavra comunicar origina-se do latim communicare que significa "pôr em comum"(1). A comunicação interpessoal pode ser definida como um conjunto de movimentos integrados, que calibra, regula, mantém e, por isso, torna possível a relação entre os homens ${ }^{(2)}$. Essa comunicação pode ser dividida em verbal (associada às palavras expressas por meio da fala ou da escrita) e em não-verbal (desenvolvida através de gestos, silêncio, expressões faciais, postura corporal, entre outros ${ }^{(3)}$.

Destacamos que as pesquisas acerca da interação com pacientes nas UTIs abordam, majoritariamente, a comunicação com pacientes que estão conscientes. Nesse sentido, encontram-se, por exemplo, estudos sobre formas de transmissão de mensagens através da comunicação não-verbal, uma vez que nesse ambiente há prevalência de pacientes com sua capacidade de expressão verbal afetada (ex.: entubação orotraqueal, traqueostomia) ${ }^{(4-5)}$.

No entanto, este trabalho pretende abordar a comunicação com pacientes sedados que, conseqüentemente, se encontram com seu nível de consciência alterado. Ressaltamos que consciência pode ser definida como "atributo pelo qual o homem pode conhecer e julgar sua própria realidade" ${ }^{(6)}$, é o "conhecimento imediato da sua própria atividade psíquica"(6).

Dentro de um contexto reflexivo, a compreensão mais profunda sobre a consciência humana e o papel da mente no processo de re-equilíbrio vital pode minimizar a ansiedade dos profissionais e estender as intervenções para além do cuidado físico e do controle técnico dos monitores, almejando atingir as demais dimensões humanas, potencializando-as. Como vem sendo preconizado nos últimos anos, devemos compreender/ cuidar do ser humano holisticamente, buscando atender todas as suas necessidades as quais formam uma unidade, um ser biológico, social, psicológico e espiritual ${ }^{(7)}$.

O comprometimento de algumas funções cerebrais e sensoriais não implica necessariamente na inexistência perceptual; a diferença está na possibilidade de expressão do que é percebido ${ }^{(7)}$.

Relacionando a reflexão anterior com a comunicação não-verbal, no caso, o toque, estudos com pacientes internados em unidades de terapia intensiva mostram que o toque de familiares, enfermeiros e médicos pode alterar o ritmo cardíaco do paciente, o qual chega a diminuir, quando os enfermeiros seguram suas mãos ${ }^{(8)}$.

Uma reflexão histórica sobre como o corpo e o toque são percebidos ressalta a possibilidade do mundo da tecnologia avançada substituir esse instrumento próprio do ser humano. "O afago, o aperto de mão, oferecendo apoio e suporte, ou mesmo o olhar carinhoso e amigo parece não ser mais necessário. A máquina passa a realizar o cuidado e a cuidadora a ocupar-se, absorvendose e concentrando-se no manuseio da mesma, por vezes esquecendo o ser humano a ela conectado"(9).

$\mathrm{Na}$ comunicação há o envolvimento do comportamento recíproco entre as pessoas que estão se relacionando, o que significa que não existe um fluxo de comportamento numa só direção(1). Destaca-se a afirmação que não há como não nos comunicarmos ${ }^{(10)}$, com ou sem intenção, sempre há a transmissão de mensagens uma vez estabelecida a interação.

Partindo-se dessa premissa, uma vez existindo a comunicação com o paciente sedado, cabe compreender como a enfermeira expressa sua percepção na abordagem verbal ou não-verbal. Destacamos a relevância de uma compreensão do comunicar-se com o paciente sedado a partir da vivência de quem cuida desses pacientes, as enfermeiras intensivistas, além disso, uma vez levantada a existência dessa comunicação, desvelar como ela ocorre. 
A comunicação é parte do tratamento do paciente e ficar conversando com ele, muitas vezes, é o próprio remédio.

(Rebecca Bebb)

\section{METODOLOGIA}

Tendo como objetivos a compreensão do comunicar-se com o paciente sedado, através da vivência/ experiência de enfermeiras que cuidam desses pacientes e, uma vez levantada sua existência, desvelar como essa comunicação ocorre, a pesquisa qualitativa na vertente fenomenológica, na modalidade da estrutura do fenômeno situado, mostrou-se a mais adequada.

A região de inquérito foi a Unidade de Terapia Intensiva de um Hospital Escola da cidade de São Paulo. A população constituiu-se de 10 enfermeiras que trabalham na unidade em que foi realizada a pesquisa e que concordaram em participar. Esse número não foi prédeterminado, pois o encerramento das entrevistas ocorreu a partir do momento em que foi constatada a invariância do fenômeno ${ }^{(11)}$.

\section{Operacionalização}

Após a aprovação do projeto pelo Comitê de Ética em Pesquisa da instituição onde foi realizado o estudo, uma das pesquisadoras abordou as enfermeiras durante o mês de novembro de 2001, esclarecendo-as sobre os objetivos do estudo, a voluntariedade de participação e a garantia do anonimato, verbalmente e em forma de documento (Termo de Consentimento Livre e Esclarecido). Após os esclarecimentos, verificou-se o interesse dos sujeitos em participar e, os que concordaram, assinaram o Termo de Consentimento, iniciando-se, dessa forma, a coleta de dados.

\section{A obtenção dos discursos}

Os discursos foram obtidos através de entrevistas individuais, as quais foram gravadas em fita cassete, mediante o consentimento dos entrevistados. As questões norteadoras da entrevista foram: Como é para você comunicar-se com um paciente sedado? Diante das respostas, nos casos em que o entrevistado levantou a existência de comunicação, foi feito o seguinte questionamento: Como acontece essa comunicação? Após as entrevistas, as falas foram transcritas e iniciouse a análise dos discursos obtidos.

O momento da análise

Seguindo o referencial metodológico adotado ${ }^{(11)}$, a análise seguiu os momentos apresentados a seguir:

1. O sentido do todo (compreensão da linguagem do sujeito): neste momento houve um "mergulho" no sentido global dos discursos através da leitura;

2. Discriminação das unidades de significado: em cada discurso transcrito foram grifados e numerados os trechos que possibilitavam a percepção da essência do fenômeno; 3. Transformação das expressões cotidianas na linguagem do pesquisador: essa transformação é necessária porque "as descrições ingênuas feitas pelos sujeitos expressam, de maneira oculta, realidades múltiplas, as quais o pesquisador deseja elucidar os aspectos psicológicos em profundidade adequada para o acontecimento"(11).

4. Síntese das unidades de significado transformadas em proposições: as unidades de significado foram agrupadas e divididas em temas gerais a partir das convergências e divergências presentes nos discursos.

\section{COMPREENDENDO O FENÔMENO}

A partir da análise dos dados desvelamos quatro categorias temáticas:

1. Comunicação com o paciente sedado x grau de sedação

Diante dos discursos obtidos, destaca-se a relação existente entre o grau de sedação em que o paciente se encontra e o estabelecimento da comunicação enfermeiro-paciente. De acordo com a quantidade de droga sedativa administrada e a forma como o paciente responde a essa sedação, há ou não a comunicação.

... é difícil porque... depende da sedação... tem hora que $(0$ paciente) te responde, tem hora que não.

Algumas enfermeiras relatam que não há comunicação com o paciente que se encontra em um grau de sedação profundo, uma vez que não existe resposta aos estímulos. Outras relatam que, nessa situação, a comunicação é dificultada.

Quando a sedação tá muito alta... não tem como você se comunicar.

... se ele estiver sedado eficazmente, a minha condição de estar me relacionando com ele é muito pequena. 
Por outro lado, quando o paciente encontra-se em um estado de sedação superficial, existe a possibilidade de estabelecer uma comunicação, mesmo que seja parcial ou prejudicada.

Quando a sedação estivesse ineficaz... ele conseguiria me responder... existiria uma comunicação parcial.

Fica claro, em alguns discursos, a dissociação entre a dose do fármaco administrado para a sedação e o grau de sedação em que o paciente se encontra, pois, com a sedação padrão que a gente usa, com $30 \mathrm{ml} / \mathrm{h}$ ele tá entendendo o que você tá falando... e tem pacientes que com $5 \mathrm{ml} / \mathrm{h}$ ficam totalmente entregues.

Outro ponto destacado em alguns discursos é o fato da sedação elevada ser supostamente melhor para o paciente que está na UTI já que ... o paciente só suporta mesmo porque está sedado, uma vez que o tratamento na UTI é, na maioria das vezes, invasivo, agressivo e até doloroso.

... dependendo do estado do paciente é importante que ele esteja bem sedado.

Esse fato é reforçado por um estudo no qual se destaca a vivência na UTI, descrita pelos pacientes, como uma experiência de solidão e desamparo, onde eles se sentem perdidos, controlados (por máquinas) e inseguros diante da incerteza de seus destinos. Eles encontram-se desconfortáveis fisicamente e inseguros emocionalmente, resultando em reações que variam do silêncio ao choro e à agitação ${ }^{(12)}$.

A discussão sobre esse assunto ocorre como contraponto diante da impossibilidade de comunicar-se com o paciente sedado, pois ... embora você perca em troca com ele, e que é superimportante... eu acho que nesse momento ainda é melhor ele não sentir dor (estando sedado).

Lembramos que as indicações sugeridas para a sedação são: aliviar a ansiedade e o medo, controlar estados confusionais agudos, facilitar o sono, diminuir o metabolismo, facilitar a realização de procedimentos e facilitar a ventilação mecânica ${ }^{(13-14)}$.

Também relativo ao grau de sedação, a comunicação, nesse contexto, aparece como instrumento de mensuração da eficácia e profundidade da sedação, ou seja, da forma como o paciente está respondendo às drogas que estão sendo administradas, destacando que a escala de Ramsey é a mais utilizada para avaliar o grau de sedação do paciente ${ }^{(13)}$.

... é muito importante (a comunicação) até pra... fazer essa medida da escala de Ramsey.

Encontramos, portanto, dentro desse tema, a comunicação com o paciente sedado como algo dependente da resposta enviada pela pessoa que se encontra sob sedação.

2. Comunicação com o paciente sedado $x$ capacidade de percepção atribuída

A reflexão acerca da percepção por parte do paciente sedado é levantada constantemente.

... eu acredito que ele está ouvindo, eu acho que ele está sentindo....

... na verdade ele tá sentindo que tá sendo manipulado.

Em um dos discursos, a dificuldade em comunicar-se com o paciente sedado está baseada, principalmente, na dúvida acerca da percepção do indivíduo.

... eu não sei, se mesmo sedado, ele vai tá ouvindo, ele vai tá sentindo, ou não...

Uma das enfermeiras lembra que a audição é um dos últimos sentidos a perder, porém existe o questionamento sobre até que ponto ele tá entendendo.

Contrapondo-se ao primeiro tema, citado anteriormente, ressaltamos que $50 \%$ das enfermeiras entrevistadas estabelecem algum tipo de comunicação com o paciente sedado independentemente do grau da sedação, ou seja, independente da obtenção de algum tipo de resposta.

Em um dos discursos, a enfermeira refere que, apesar de sentir falta de contactuar com o paciente, ou seja, de obter uma resposta, ela sempre conversa com ele e chama-o pelo nome.

Quando as enfermeiras afirmam não ter resposta do paciente sedado profundamente, elas abordam a questão da ausência de expressão do paciente, entretanto, devemos lembrar a dicotomia existente entre percepção e expressão do que é compreendido. $O$ comprometimento de funções cerebrais e sentidos não implicam, necessariamente, na inexistência perceptual ${ }^{(7)}$.

"Reconhecer os sentimentos do doente é fundamental para o enfermeiro, pois é através dessa compreensão que ele percebe as necessidades reais do paciente e pode realizar um plano de cuidados sistematizado, considerando a pessoa como um todo, e desenvolvendo uma postura empática"(2).

3. Valorização da comunição com o paciente sedado

Através dos discursos, algumas atribuições foram consideradas sobre comunicar-se com o paciente sedado, dentre elas destacam-se aquelas mencionadas a seguir.

Primeiramente, a aproximação que a comunicação estabelece entre o cuidador e o paciente. 
Lembrando que a ética está sempre associada à presença, que é um dos componentes mais importantes do cuidado humano. Na verdade, "o cuidado humano, pelas suas próprias características, é considerado a própria ética da enfermagem" ${ }^{\text {(9) }}$.

Entretanto, houve grande evolução técnica no que diz respeito aos enfermeiros e profissionais da saúde, porém, como técnica não significa ética, nem sempre se consegue transpor o discurso de humanidade nas pequenas coisas ${ }^{(2)}$.

Outra atribuição destacada sobre o comunicarse com o paciente sedado é que esse ato torna-o mais calmo. Somando-se a isso, estabelecer essa comunicação é importante porque possibilita uma troca com o paciente; o enfermeiro passa a ter maior possibilidade de perceber o que ele está sentindo; permite a mensuração do grau de sedação; além de ser um passo anterior à invasão da privacidade desse indivíduo que está com sua capacidade de expressão afetada e em quem o enfermeiro realiza, além do banho, muitos outros procedimentos que invadem sua individualidade.

Por último, a partir dos discursos, também é possível afirmar que a comunicação com o paciente sedado é necessária, é função do enfermeiro, é algo que o diferencia como profissional e, algumas vezes, é um ato condicionado, sem reflexão.

Somando-se aos valores atribuídos à comunicação com o paciente sedado, obtivemos relatos acerca de fatores que dificultam o estabelecimento dessa comunicação, por exemplo, ...com o tempo (a gente) acaba criando uma certa barreira... conforme a coisa vai ficando meio que corrida, a gente vai ficando um pouco mais frio também.... Nesse caso, a rotina, a escassez de tempo, e a falta de reflexão desencadeiam essa dificuldade.

... você não estar totalmente presente (com o paciente) é muito frustrante.

A falta de estrutura da unidade, entendida como fator facilitador para o estabelecimento de comunicação, também é citada nos discursos.

Uma pesquisa revela que a UTI, por ser um local que enfatiza os recursos materiais e a tecnologia, contribui para comportamentos automatizados, onde o diálogo e a reflexão crítica não encontram espaço, inclusive pelas situações contínuas de emergência, pela gravidade dos pacientes e pela dinâmica acelerada do serviço. Diante disso, percebe-se que as "atividades-meios" acabam transformadas em "atividades-fins", desviando o foco da atenção que deveria estar no paciente ${ }^{(12)}$.

4. Formas de comunicação com o paciente sedado

Com exceção de apenas um discurso, todos abordaram formas distintas de se comunicar com 0 paciente sedado. A comunicação verbal é citada com freqüência, porém, o não-verbal também é destacado:

... tô conversando sempre com o paciente mesmo que ele esteja arresponsivo.

(a comunicação ocorre)... só por mímica, expressões faciais... ouvir o sim ou não com a cabeça... perceber pelo grau de agitação do doente...

...quando dá pra você se comunicar com ele é através de gestos, escrita...

... eu já gosto mesmo de, de me comunicar com o paciente, tocar, conversar... dar atenção.

(a comunicação ocorre através) do toque, da conversa e até brincando...

chamar pelo nome é tão gostoso, tão aconchegante...

... eu dei feliz Ano Novo para toooodos os pacientes, tavam todos eles sedados... são tal horas, tá começando o ano tal... que o senhor ou a senhora saia bem daqui...

... a gente fala... a gente toca....

... (o paciente se expressa) através de gesto, de sinal ou, responder ao estímulo...

Destacamos que a comunicação pode ser concebida como um sistema de múltiplos canais, em que o ator social participa em todos os momentos, desejando ou não, por seus gestos, olhares, silêncio e até na sua ausência $^{(2)}$.

Diante desses relatos, observamos que, apesar de algumas enfermeiras acreditarem na existência da comunicação independente do grau de sedação, e outras, considerarem esse fator nos diferentes momentos em que é estabelecida a comunicação, essa ocorre através do verbal e do não-verbal (expressões faciais e corporais, toque, brincadeiras). Destaca-se ainda que, na maior parte das vezes, os pacientes não se manifestam claramente.

\section{SÍNTESE}

A análise dos discursos e a obtenção dos quatro temas gerais contidos nas descrições proporcionaram a compreensão do fenômeno comunicar-se com o paciente sedado, a partir da vivência e experiência de enfermeiras intensivistas, sob duas perspectivas:

- a primeira definindo o fenômeno em função do grau de 
sedação, onde metade dos sujeitos acreditam que comunicação e grau de sedação sejam processos interdependentes; os demais acreditam tratar-se de fenômenos independentes;

- a segunda revela essa comunicação como algo dependente da capacidade de percepção e/ou expressão por parte do paciente, independente do grau de sedação.

Essas duas perspectivas de perceber o fenômeno, entretanto, convergem a partir do momento em que $100 \%$ dos discursos obtidos revelaram a existência da comunicação com o paciente sedado, mesmo que em momentos diferentes e de formas distintas.

Diante dessa revelação, foi destacado, também, que se comunicar com o paciente sedado é um fenômeno difícil, seja pelo grau de sedação, pela falta de tempo, de reflexão e de estrutura da unidade; seja pela dúvida acerca da percepção do paciente sedado diante da mensagem recebida. Em relação a essa percepção por parte do paciente, destaca-se a crença e, algumas vezes, a dúvida acerca da audição e da sensibilidade do paciente que está sedado.

O comunicar-se com o paciente sedado foi desvelado, de modo geral, como um fenômeno que:

- aproxima o cuidador do paciente;

- é importante por proporcionar uma troca entre ambos, aumentando a percepção sobre o que o paciente está sentindo;

- é importante por ser um passo anterior à invasão da privacidade do paciente;

- é um instrumento de mensuração da profundidade da sedação;

- é necessário;

- acalma o paciente;

- é função do enfermeiro;

- diferencia o profissional;

\section{REFERÊNCIAS BIBLIOGRÁFICAS}

1. Mendes IAC. Enfoque humanístico à comunicação em enfermagem. São Paulo (SP): Sarvier;1994.

2. Silva MJP. Percebendo o ser humano além da doença - o não-verbal detectado pelo enfermeiro. Nursing 2001; 41(4):1420.

3. Silva MJP. Comunicação tem remédio - a comunicação nas relações interpessoais em saúde. São Paulo (SP): Gente; 1996

4. Cercal M, Toledo RVA, Antônio ALO, Sadala MLA, Oliveira RA. Estudo da comunicação enfermeira-paciente como procedimento terapêutico no cuidado do paciente intubado. Rev Soc Cardiol Estado de São Paulo 1994; 4 (4 Supl A):1-9.
- algumas vezes, ocorre como um ato condicionado, sem reflexão.

Seguindo os objetivos deste estudo, foi desvelado, ainda, como ocorre a comunicação com o paciente sedado. Essa acontece, sob a perspectiva da enfermeira, através da verbalização, do toque, da atenção e das brincadeiras; $\mathrm{e}$, sob a perspectiva do paciente, através da escrita (pacientes com sedação superficial) e de expressões faciais e corporais, entretanto, na maioria das vezes não há manifestação por parte do paciente, a não ser pelo silêncio verbal e corporal.

É relevante uma discussão sobre a compreensão que as enfermeiras possuem do que vem a ser comunicação. De acordo com os discursos, algumas enfermeiras afirmam não haver comunicação com o paciente sedado profundamente, pois não existe resposta. Nesse sentido, a comunicação é compreendida como uma "via de duas mãos", na qual uma informação é enviada e dela espera-se a obtenção de um retorno. Porém, as enfermeiras que estabelecem a comunicação independente do grau de sedação, aparentemente, também consideram a possibilidade da comunicação existir como uma "via de mão única", na qual o que importa é a tentativa de transmitir uma mensagem, ou até obter um retorno, porém não imediato, como é expressado no seguinte discurso ...eu acho que ele tá sentindo e que ele vai perceber o contato que você teve com ele quando ele estiver acordado.

Que o homem seja capaz de considerar-se a si mesmo é o grande prodígio da natureza, pois ele não consegue conceber o que é seu corpo e muito menos o que é seu espírito e, finalmente, como o corpo pode se unir ao espírito. Este é o cume de sua dificuldade e, no entanto, é a essência do seu ser.

(Pascal)

5. Zago MMF, Galvão CM, Okino N. A comunicação com pacientes de UTI submetidos a entubação orotraqueal. In: Anais do 1 Simpósio Brasileiro de Comunicação em Enfermagem; 1988 mai 2-4; Ribeirão Preto; SP. Ribeirão Preto: USP/EERP; 1988.

6. Ferreira $\mathrm{ABH}$. Minidicionário da língua portuguesa. $3^{\mathrm{a}} \mathrm{ed}$. Rio de Janeiro (RJ): Nova Fronteira; 1993.

7. Silva MJP, Dobbro ERL. Reflexões sobre a importância da mente na recuperação do paciente em coma. O mundo da Saúde 2000; 24(4):249-54

8. Lynch JJ. The simple act of touching. Nursing 1978; 8(6):326.

9. Waldow VR. Cuidado humano - o resgate necessário. Porto Alegre (RS): Sagra Luzzatto; 1998. 
10. Watzlawick $P$, Beavin JH, Jackson DD. Pragmática da comunicação humana. São Paulo (SP): Cultrix; 1967.

11. Martins J, Bicudo MAV. Pesquisa qualitativa em psicologia: fundamentos e recursos básicos. São Paulo (SP): Moraes; 1989.

12. Franco GRRM. A unidade de terapia intensiva: um estudo sobre a comunicação entre profissionais e pacientes. [dissertação]. São Paulo: Escola Paulista de Medicina; 1999. 13. Knobel E. Condutas no paciente Grave. São Paulo (SP): Atheneu; 1994.

14. Slullietl A, Sousa AM. Analgesia, sedação e bloqueio neuromuscular em UTI. Medicina, 1998; 31(4):507-16. 